\title{
$O$ ano da morte de Lisboa: Pessoa e Saramago em heteronímias tanatográficas
}

\author{
Ana Clara Magalhães de Medeiros \\ Universidade Federal de Alagoas \\ Augusto Rodrigues da Silva Junior \\ Universidade de Brasília
}

\begin{abstract}
Resumo
Lisboa é palco e mote da ação no romance passado n'O ano da morte de Ricardo Reis — publicação de José Saramago (1984) aqui estudada. Analisamos as deambulações de um heterônimo pessoano, Ricardo Reis, refeito em prosa pelo português Nobel de literatura. Acompanhando ainda os passeios de despedida de um Pessoa defunto pela capital lusitana, descortina-se uma cidade chuvosa, nublada pelo mal-estar (freudiano) e pela ascensão do salazarismo. As diversas poéticas pessoanas encorpam o romance, operando também neste trabalho como ferramentas discursivas para se pensar o indivíduo e a cidade, a cidade em tempos de totalitarismo. Pelas janelas do tanatográfico livro dos anos 1980, revisitamos uma urbe desassossegada que conserva na poesia (ameaçada pela morte como tudo o que vive) seu espaço último de plenitude.
\end{abstract}

Palavras-chave: Saramago; Pessoa; cidade; tanatografia.

\begin{abstract}
Lisbon is core and stage in José Saramago's publishing The Year of The Death of Ricardo Reis (1984) hereby studied. The wanderings through one of Pessoa's heteronym, Ricardo Reis, remade in prose by the Portuguese Nobel-prized, are analyzed in this very study. Following an already deceased Pessoa and his farewell strollings through the Lusitanian capital, it is uncovered a rainy city, clouded by the Discontents (Freud) and the Salazarism ascension. The diversities of Pessoa's poetry embodies the novel, also working as a discursive tool to think about the individual and the city, the city in totalitarian times. Across this 80 s thanatographic book, we revisit a restless town which preserves in poetry (threatened by death as everything living) its last space of completeness.
\end{abstract}

Keywords: Saramago; Pessoa; city; thanatography.

Recebido em: $31 / 03 / 19$

Aprovado em: 06/07/19

A dinâmica deambulante de personagens pelas "ruas ermas de Lisboa" (SARAMAGO, 2010 , p. 27), refina e estiliza a imagem da capital portuguesa no romance $O$ ano da morte de Ricardo Reis (1984), de José Saramago. Uma geopoesia da composição romanesca invoca 
leitura profunda do espaço citadino, investindo em um arquivo literário de experiências urbanas a partir de Fernando Pessoa. Pessoa poeta e fazedor de poetas, falecido na Lisboa de 1935. Saramago, poeta e romancista, consolidando-se na cena da literatura mundial no ano de 1984.

As vozes que ecoam e os seres que se encontram nesse romance seguem para além da superfície encantadora do visível, de modo a transformar o passeio-viagem em verdadeira força integradora e renovadora da imaginação: a heteronímia. O Pessoa que Maria Aliete Galhoz definiu como o "poeta que tende já para a imortalidade" (GALHOZ, 2005, p. 15) encontra-se na narrativa morto, sepultado, mas experimentando os últimos nove meses de deambulação cadavérica pela cidade onde viveu, escreveu e se inscreveu no universo literário. Pelos passos de um autor defunto, desponta a condição tanatográfica (SILVA JR., 2014). Pelas idas e vindas de um heterônimo redescoberto, em condição romanceada, os elementos urbanos falam com o leitor: "é a cidade silenciosa que os assusta, porventura morreu a gente nela e a chuva só está caindo para diluir em lama" (SARAMAGO, 2010, p. 11). Na agilidade do espírito, que passeia por ruas rotas, e na leveza da alma, que voa em parábolas, é possível perceber um narrador que se aproxima de modo peculiar da cidade:

Seguiu o caminho das estátuas, Eça de Queirós, o Chiado, D’Artagnan, o pobre Adamastor visto de Costas, fingiu que admirava monumentos, por três vezes lhes deu pausada volta, sentia-se como se estivesse a brincar aos polícias e ladrões (SARAMAGO, 2010, p. 458).

Neste artigo, evidenciamos elementos entrevistos nos espaços do romance em que a arquitetura lusitana, feita de ladeiras e palavras, indica direções. No entanto, mal se encerra um capítulo, perdemo-nos nas vias do fingimento e do desassossego: "A rua está calçada de pedra grossa, irregular, é um basalto quase preto onde saltam os rodados metálicos das carroças" (SARAMAGO, 2010, p. 46). A geopoesia saramaguiana se dá entre "Tropos e grafias que podem ser reconhecidas em vozes e corpos, mapas e viagens" (SILVA JR., 2018, p. 55). Nesse sentido, nosso esforço, aqui, é o de mapear uma geopoesia lusitana pelas calçadas irregulares da composição romanesca d' $O$ ano da morte de Ricardo Reis.

Compete-nos dizer palavras gerais sobre o romance aqui descortinado, para situar o leitor nessa etnocartografia heteronímica. Trata-se de obra nublada, histórica e poetizada, que faz ecoar versos de Fernando Pessoa, bem como de heterônimos seus, sobretudo Ricardo Reis - que aparece desde o título. As crianças que desembarcam do Higland Brigade já aspiram palavras soltas e caeirianas. A prosa contumaz e o âmago sonolento evocam um desconhecido Livro de desassossego que recebe o nome de The God of the labyrinth. Latente alusão saramaguiana a texto de Jorge Luis Borges, aparecido em Ficciones (2011) e nunca lido completamente por Ricardo Reis: 
Se somente isto sou, pensa Ricardo Reis depois de ler, quem estará pensando agora o que eu penso, ou penso que estou pensando no lugar que sou de pensar, quem estará sentindo no lugar que sou de sentir, quem se serve de mim para sentir e pensar, e, de quantos inúmeros que em mim vivem, eu sou qual, Quain, que pensamentos e sensações serão os que não partilho só por me pertencerem, quem sou eu que outros não sejam ou tenham sido ou venham a ser (SARAMAGO, 2010, p. 24).

Um Livro de desassossego (e não exatamente do desassossego) que se passa em Lisboa, no ano de 1936, onde são problematizados fenômenos históricos que marcaram o breve século $X X$ - expressão de Eric Hobsbawm (2008). Estamos no ano de acirramento do Estado Novo português, da eclosão de revolta comunista dos marinheiros lisboetas e da Guerra Civil espanhola. Os fascismos dos anos 1930 espraiados pela Europa são intuídos nas ruas e hotéis, nos teatros e cinemas, nas estátuas e nos seres comuns - trabalhadores, feito Lídia e Daniel, personagens revolucionários no romance em questão.

Toda a problemática econômica e política advinda desse conturbado momento histórico está entremeada à subjetividade dos personagens numa conurbação entre a Lisboa que foi e a Lisboa que se narra: Ricardo Reis, médico e poeta, relaciona-se afetivamente com uma criada de hotel chamada (caprichosamente) Lídia - que é um nome comum no mundo lusófono, ao contrário de Cloe e Neera, outras musas do heterônimo poeta. Além desta, cultiva amores por Marcenda, de nome também retirado das odes do próprio Reis: "Saudoso já deste verão que vejo,/ [...] E colho a rosa porque a sorte manda./ Marcenda, guardo-a; murche-se comigo/ Antes que com a curva/ Diurna da terra" (RICARDO REIS, 1960, p. 243). No enredo, ela é uma jovem cuja mão esquerda sofre paralisia. Destaque-se: está paralítica, saramaguianamente murcha, a mão esquerda.

Atreladas a este personagem central, aparecem figuras coadjuvantes que são marionetes sem que disso se deem conta, como o dono do Hotel Bragança, Salvador, e o capataz da polícia salazarista, Vítor, soldado que persegue Reis nos seus passeios noturnos pela cidade. Ainda, alguns passantes colorem e amplificam a narrativa: uma dupla de velhinhos leitores de jornal em frente à estátua do gigante Adamastor no Alto de Santa Catarina e o marinheiro Daniel, irmão de Lídia, personagem coadjuvante que morre em rebelião comunista junto aos seus companheiros de classe na "Revolta dos Marinheiros" (episódio histórico passado em 1936).

Uma galeria de personagens também foi intuída por Pessoa e seus heterônimos. Principalmente pelo Álvaro de Campos das "[...] metafísicas perdidas nos cantos dos cafés de toda a parte", da "pequena" que "come chocolates"; que se destacou pela episódica "Tabacaria": "E hoje não há mendigo que eu não inveje"; "o Dono da Tabacaria (que) chegou à porta e ficou à porta"; “[...] um homem entrou na Tabacaria (para comprar tabaco?)” (ÁLVARO DE CAMPOS, 1960). O leitor de Saramago e Pessoa, nesta altura, já enforma um cenário romanesco, que Álvaro de Campos enxerga e compõe da janela do seu quarto: 
O homem saiu da Tabacaria (metendo trôco na algibeira das calças?).

Ah, conheço-o; é o Estêves sem metafísica.

(O dono da Tabacaria chegou à porta.)

Como por um instinto divino o Estêves voltou-se e viu-me.

Reconstruiu-se-me sem ideal nem esperança, e o Dono da Tabacaria sorriu (ÁLVARO DE CAMPOS, 1960, p. 323-328).

Saramago, em seu romance, aproxima tempos paralelos, cidades sobrepostas. Um narrador que herda de Campos o olhar pelas janelas impossíveis e as relações com a cidade. Fantasmagorias de heterônimos que, cada qual à sua maneira, fazem ecoar escritas amalgamadas. Para Pessoa, escrever é tentar fingir (recriando) um (outro) mundo. Imitar não apenas, mas escrever para o desassossego, escrever porque sempre é tempo de desassossegar: "no destino, mais vale passar silenciosamente e sem desassossegos grandes, isto escreveu um dia, isto é o que em todos cumpre" (SARAMAGO, 2010, p. 425). Neste romance de Lisboas extremas (1935-1974), o mundo é uma cidade por-fazer.

Uma cidade, uma aldeia, seus rios e nevoeiros: "Da minha aldeia vejo quanto da terra se pode ver o Universo.../ Por isso minha aldeia é tão grande como outra terra qualquer,/ Porque sou do tamanho do que vejo/ E não do tamanho da minha altura" (ALBERTO CAEIRO, 1960, p. 143). Pequenos detalhes existenciais podem ser transformados em fingimentos quando um poeta busca o espaço para compor sua poética. Diante de uma coleção de fingimentos que vai de 1936 a 1974 (mais especificamente até o 25 de abril) e de 1935 a 1984 (quando da publicação do romance), há muitos vestígios (pessoanos, camonianos) espalhados pela Lisboa de Saramago. Pequenos traços impressos do tamanho de um romance, sensações pictografadas que cabem numa ode, recordações desenhadas de um defunto ortônimo (tanatografado), sonhos riscados pelos personagens e pessoas ordinárias tão plenos de desejos despontados de lugares-comuns.

Veremos que, na Lisboa daquele ano fatídico - em que a cidade de Pessoa precisa subsistir no ano subsequente ao ano de sua morte - impera um mal-estar generalizado, estilizado em chuva e mau tempo meteorológico no romance. Quando empregamos o termo destacado, evidentemente trazemos Sigmund Freud para a arena e ponderamos com ideias de seu O mal-estar na civilização (1930):

nossas possibilidades de felicidade sempre são restringidas por nossa própria constituição. Já a infelicidade é muito menos difícil de experimentar. O sofrimento nos ameaça a partir de três direções: de nosso próprio corpo, condenado à decadência e à dissolução, e que nem mesmo pode dispensar o sofrimento e a ansiedade como sinais de advertência; do mundo externo, que pode voltar-se contra nós com forças de destruição esmagadoras e impiedosas; e, finalmente, de nossos relacionamentos com os outros homens (FREUD, 2006, p. 84-85). 
As direções ocasionadoras do sofrer aparecem e emaranham-se n' $O$ ano da morte de Ricardo Reis. A dissolução do corpo, sua corrupção, permanece como lembrete - destino ao longo da narrativa, que conta os nove meses derradeiros do fantasma de Pessoa. Personagem que alerta o heterônimo: "Meu caro Ricardo Reis, eu já nem leio" (SARAMAGO, 2010, p. 144), deteriorado está o corpo fenecido. O poeta de Orpheu é agora, em prosa, desencarnado, como outrora intuiu Leyla Perrone-Moisés: "para Pessoa, o cotidiano foi sua poesia, e o corpo desencarnou-se, cifrado nos rastos de tinta sobre o papel, atestando indefinidamente sua impossibilidade de sentir-se real e inteiro" (PERRONE-MOISÉS, 2001, p. 96).

A causa terceira do sofrer, advinda da relação com o outro, avulta na impossibilidade mesma de Reis relacionar-se com alguém, especialmente com uma parceira amorosa — notese o sumiço de Marcenda da trama, escanteada pelo poeta das odes, ou a sua incapacidade de reconhecer e experimentar a realidade da criada Lídia, a quem pede que aborte o filho de ambos.

Contudo, num mundo em que "nada é inteiro" — já asseverava o Pessoa da Mensagem, no último canto do pretenso poema épico (PESSOA, 1960, p. 89) - , damos destaque ao sofrimento que o psicanalista menciona advir do mundo externo, que pode se voltar contra nós e volta-se na obra saramaguiana. Na publicação de 1984, Lisboa torna-se palco para a grande tempestade europeia que assolou o breve século XX: o totalitarismo.

Saramago, ao enredar-se a Pessoa, lança-se no "Ano da morte de Lisboa" - que é também o ano da morte da Europa. A cidade humaniza-se para assistir à derrocada de uma época. As figuras inter-relacionam-se, então, numa urbe que transborda de temporal e mal-estar (de civilização):

Quem disser que a natureza é indiferente às dores e preocupações dos homens, não sabe de homens nem de natureza. Um desgosto, passageiro que seja, uma enxaqueca, ainda que das suportáveis, transtornam imediatamente o curso dos astros, perturbam a regularidade das marés, atrasam o nascimento da lua, e, sobretudo, põem em desalinho as correntes de ar, o sobe-e-desce das nuvens, basta que falte um só tostão aos escudos ajuntados para pagamento da letra em último dia, e logo os ventos se levantam, o céu abre-se em cataratas, é a natureza que toda se está compadecendo do aflito devedor. [...] E não reparam que doutra maneira não poderia ser entendido este contínuo mau tempo de há meses, ou anos, que antes não estávamos nós cá, os vendavais os dilúvios, as cheias, já se falou o suficiente da gente desta nação para reconhecermos nas penas delas a explicação da irregularidade dos meteoros, somente recordemos aos olvidadiços a raiva daqueles alentejanos, as bexigas de Lebução e Fatela, o tifo de Valbom, e, para que nem tudo sejam doenças, as duzentas pessoas que vivem em três andares de um prédio de Miragaia, que é no Porto, sem luz para se alumiarem, dormindo a esmo, acordando aos gritos [...] o resto componha-o a imaginação, para alguma coisa há-de ela servi-vos (SARAMAGO, 2010, p. 187-188).

A imagem do caos, tão comum à obra saramaguiana, apresenta-se neste romance pelo mau tempo (meteorológico). Havendo dúvidas sobre o sentido da insistência da chuva (que encharca 
não apenas Lisboa, como se vê na citação destacada, mas uma série de vilarejos e regiões mais interioranas do país) ao longo da trama, fica agora evidente pelas palavras do narrador. A voz que conta sente-se em condições de declarar que já deu a conhecer suficientemente a "gente desta nação". Por ela é que se enfurece a natureza, com seus "vendavais", "dilúvios" e "cheias". O narrador não poderia ser mais explícito na justificativa do temporal que inunda a trama e a vida: "para reconhecermos nas penas delas [da gente desta nação] a explicação da irregularidade dos meteoros [sociais, culturais]".

As tais penas sofridas pelo povo português, como causa externa do sofrimento (conforme interpretação freudiana) não deixam de ser informadas ao leitor (que, portanto, torna-se um "olvidadiço" senão se mantiver abismado delas). A raiva dos alentejanos, para quem conhece minimamente a condução econômica de Salazar, parece motivada pelo atraso produtivo de um país eminentemente rural, que demonstrava seu aspecto mais atrasado na indisposição para promover qualidade de vida ao camponês. Lembre-se de que, no tocante à produção agrícola, tal política incluía minimizar os custos de produção (salários baixos, mercado local de potencial mínimo) e maximizar o lucro (MOSCA, 2007).

Da região situada mais ao sul português somos levados para as antigas freguesias de Fatela (no interior central lusitano) e de Lebução (no extremo norte do país) onde a população pobre contagiava-se facilmente com a bexiga (varicela), que costumava ser fatal. Ainda, o narrador menciona a febre tifoide em região próxima ao Porto (Valbom) e, "para que nem tudo sejam doenças", lembra a condição de cortiço em que se amontoavam habitantes do litoral. O cenário é precário e, em algumas linhas, recompõe-se a miséria que toma desde o norte ao sul do país: "quem disser que a natureza é indiferente às dores e preocupações dos homens" não percebe que, n'O ano da morte de Ricardo Reis, a chuva que cai sobre a Lisboa de um heterônimo retornado é a lamentação perene da natureza frente à dor dos viventes na Ibéria de 1936.

Cidade sitiada pelo desgoverno do governo autoritário espalhado pelas cidades invisíveis de Portugal (CALVINO, 1990). A perspectiva do clima nublado e chuvoso em Lisboa alia atmosferas. Mais especificamente, estilizações jornalísticas, poéticas e históricas de uma imensa galeria de observação realizada pelo andarilho Ricardo Reis. Desenhando um mapa surpreendente de figuras, personagens e histórias, em diálogo com a tradição, o romance de José Saramago revisita Lisboas liminares (de 1935-1936 a 1974-1984). Conforme adverte crítica reconhecida sobre a obra, Teresa Cerdeira, assim encontra-se o vivente heterônimo:

Ei-lo, portanto, perdido nessa Lisboa revisitada, debatendo-se por nove meses num país de marinheiros naufragados em ondas de silêncio e corrupção, buscando angustiadamente uma saída para o labirinto. Entretanto não é outro o projecto do romance: colocar face a face a alienação, a situação de crise e o projecto revolucionário. O discurso narrativo trouxera de volta o heterónimo para o lançar na terra. Para perder o alheamento que a distância e a visão de mundo lhe haviam inculcado, Ricardo Reis tem, por exemplo, os jornais, mas é preciso aprender a lê-los, labirínticos que são, 
de modo a enxugar o autoritarismo fascista a mensagem encoberta que revelaria a história. Para tanto, paradoxalmente, o intelectual deve contar com a ajuda de uma camareira de hotel, quase analfabeta, mas irmã do marinheiro revolucionário Daniel (CERDEIRA, 2000, p. 274-276).

Ricardo Reis, embora inicialmente alheio pela "distância e a visão de mundo", vai, paulatinamente na narrativa, aprendendo a ler o cenário que se lhe impõe em uma Lisboa dominada por Salazar. O saldo, porém, é a desistência de ser leitor efetivo de The God of the Labyrinth e de viver essa cidade naquele tempo. A metáfora do labirinto (borgiano), retomada por Saramago, ilustra o titubeante Ricardo Reis. Como intui Walter Benjamin, em suas Passagens: "o caminho daquele que receia alcançar sua meta traçará facilmente um labirinto" (BENJAMIN, 2018, p. 563). Para um heterônimo sem metas, em um momento da história sem sonhos, no espaço de uma cidade-nevoeiro impiedosa, qualquer caminho é labirinto.

A partir de uma imagem de viagem, o exilado Ricardo Reis - que teria ficado quase “dezasseis anos" (SARAMAGO, 2010, p. 13) no Rio de Janeiro — retorna à Lisboa por conta da notícia da morte de Pessoa. Imagem vinculada à composição do próprio livro, essa chegada para visitar "o amigo" no túmulo nos integra à cidade que, por sua vez, surge num cais do Tejo: "Lisboa, Lisbon, Lisbonne, Lissabon” (SARAMAGO, 2010, p. 10).

Todos os nomes, o nome (Lisboa) dito de diferentes maneiras por diferentes crianças para o mesmo ponto de partida e de chegada: "aqui o mar acaba e a terra principia" (SARAMAGO, 2010 , p. 7). Na primeira linha epigráfica do livro, abre-se um romance em que o narrador, junto com um heterônimo voltam para assistir ao espetáculo romanceado do mundo: "Sábio é o que se contenta com o espetáculo do mundo" (RICARDO REIS, 1960, p. 259; SARAMAGO, 2010, p. 07). Nesse prólogo feito de epígrafes, revivemos gestos ancestrais de diálogos e assim renovamse os mitos (narrativos) - a exemplo de Camões e de seu gigante Adamastor. Note-se que, ao imbricar Pessoa e Camões em seu romance, Saramago inscreve-se, com autoconsciência rara na história da literatura, "no firmamento da nossa Cultura", ao lado dos dois poetas portugueses máximos (o do século XVI e o da primeira metade do XX). Se deles Eduardo Lourenço disse que se firmam "não só como grandes poetas, mas como modelos, por assim dizer, registados, da tão celebrada 'maneira portuguesa de estar no mundo"' (LOURENÇO, 2008, p. 64), menos não se pode dizer do autor morto em 2010.

Seres que se movimentam existencialmente (na busca incansável do ser pelo ser ou não ser de cada questão) enquanto o "resto é silêncio" - e Saramago não nos deixa mentir: "desde o Hamlet que nós andávamos a dizer, O resto é silêncio" (SARAMAGO, 2010, p. 39). Esse silenciamento vela um Adamastor esfíngico mudo, mas pronto para lançar o grande grito do Alto de Santa Catarina.

A imaginação íntima que cruza destinos literários - Camões, Pessoa e Saramago encarrega-se das memórias, das palavras e das imagens (símbolos visibilizados) que se renovam 
na arte de narrar com a presença da heteronímia. Nas páginas que colhem seus heróis do drama em gente pessoano - um heterônimo andante e um defunto ortônimo - encontramos um fingimento rememorador e o sentimento observador da cidade: que pode ser uma aldeia, que pode ser o mundo. Dez anos depois da Revolução dos Cravos (1974), Saramago recorre à memória das pessoas de Pessoa para voltar a ler Lisboa em momento de reconstruir liberdades: "é, portanto, a memória que condiciona a leitura da cidade, uma busca de sentido explícito e reconhecível, que a sociedade moderna já não permite" (GOMES, 1994, p. 44).

Saramago recupera, no discurso heteronímico, a "faculdade de intercambiar experiências" (BENJAMIM, 1994, p. 198) e assim possibilita o reconhecimento dos fenômenos naturais e urbanos que se fundem aos humanos. Em constante movimento no interior das cidades, diante de nossas pálpebras, que dividem o mundo recordado do mundo observado, se Lisboa pode nunca ter existido, por paradoxo, todo heterônimo pode algum dia ter existido.

A brincadeira é com o trecho de Bernardo Soares que abre o romance saramaguiano enquanto epígrafe: "Se me disserem que é absurdo fallar assim de quem nunca existiu, respondo que também não tenho provas de que Lisboa tenha alguma vez existido, ou eu que escrevo, ou qualquer cousa onde quer que seja" (SARAMAGO, 2010, p. 07). Se existir é fazer obra, todo heterônimo deixou seu nome em palavra. Pessoa agregou todos os nomes sempre levando seu nome em outro, outros. Ou então, trazendo o nome de outro ao seu - sempre em condição fingidora. O narrador de Saramago é também um fingidor e finge tão completamente que chega a transformar-se em poeta. Se ele não existiu nos anos de morte e vida de Fernando de Pessoa, é certo que o romance permitiu-lhe reviver ou reavivar os nove meses antecedentes à morte de Ricardo Reis.

A obra, ao remoer a narrativa contada por ela própria, num movimento canibalesco similar, por andarilho, ao dos personagens da Comédia de Dante, convoca o conde que devorou os filhos para apresentar uma cidade que se morde (de remorso?). Na tentativa perene de fisgar os filhos seus, leitores do romance e da história, para convocá-los à ação, conta o narrador: "Pelas ruas ermas de Lisboa anda a cadela Ugolina a babar-se de sangue, rosnando às portas, uivando em praças e jardins, mordendo furiosa o próprio ventre" (SARAMAGO, 2010, p. 27). A cidade e a metáfora ugolinas não aparecem por acaso. Combinam-se em trajetos decisivos e enformados pelo fingimento poético - numa memória viva dos anos de 1935-1936, metonímica de um longo (e aterrador) período de ditadura.

O romance espelha essa cadela anunciada no primeiro capítulo do livro. Faz menção explícita ao conde italiano Ugolino dela Gherardesca, que, dizem a crença popular e Dante, ter devorado seus próprios filhos. Assim, o narrador antecipa uma metáfora que conduzirá toda a narrativa, plena de desassossegos, amparada por uma nesga, singela, mas intermitente, de poesia. Poesia de um narrador-poeta que não se contenta com o espetáculo do mundo, mas concebe a escrita enquanto possibilidade latente de realização da plenitude humana. Tudo isso 
com um Ricardo Reis andante, em deambulações de quem assiste ao espetáculo da existência em ação. O heterônimo, como personagem de romance, não pode ser mais aquele idealista, em busca de evasões. É um ser de carne e osso, encarnado nas mais diferentes experiências do indivíduo e do individualismo à maneira portuguesa de estar no mundo.

Acompanhando as deambulações espectrais do defunto Pessoa, esse é o romance de uma espécie de trilogia da tanatografia elaborada por Saramago ao longo de sua trajetória. Embora não os abordemos aqui, os demais livros compositivos dessa possível trilogia - Todos os nomes (1997) e As intermitências da morte (2005) - trazem defuntos personagens como figuras centrais de seus enredos, suas tramas, seus desassossegos. Enquanto escrita de morte, $O$ ano da morte de Ricardo Reis articula encontros insustentáveis entre ordens ontológicas, entre o existir e o não existir, entre o ser ou não ser um heterônimo, entre ter uma vida autônoma ou viver o fingimento de um grande projeto literário. O ter de viver a despeito da morte que se alastra é condicionante no romance de 1984 — obra fulcral na poética tanatográfica de Saramago. Com a brasileira Sandra Ferreira, estudiosa da prosa do alentejano, enfatizamos:

Dessa reciprocidade entre vida e morte, aliança indissolúvel, surgem escrituras saramaguianas que investem ficcionalmente na dialética natural entre vida e morte, de modo a lembrar-nos, em espécie de memento mori contemporâneo, que somos seres que não paramos de morrer nunca e a arte é um lugar ímpar para amenizar o conflito entre querer viver e o ter de morrer que dilacera a espécie humana (FERREIRA, 2011).

No lugar artístico e filosófico ímpar que é este romance, Pessoa foi reinventado na condição menipeica de defunto. Reis desdobrado entre o ser múltiplo e o ser nada - persona comum enxertada no século dos extremos. Esses autores, pela empreitada narrativa saramaguiana revisitam uma Lisboa que o leitor pessoano já conhece do Livro do desassossego. Em tempos assim — de desassossego - , as cidades do ortônimo, dos heterônimos, dos semi-heterônimos, do narrador e dos personagens prosaicos fundem-se em uma grande voz poética que, apesar do monologismo sério e ditatorial de 1936, faz polifonia pela prosa - somando vozes múltiplas que interessam mais.

Se mencionamos sem receio o livro prosaico de autoria usualmente atribuída ao ajudante de guarda-livros Bernardo Soares, compete-nos visitá-lo: "Há em Lisboa um pequeno número de restaurantes ou casas de pasto [em] que, sobre uma loja com feitio de taberna decente se ergue uma sobreloja com uma feição pesada e caseira de restaurante de vila sem comboios" (PESSOA, 1999, p. 39).

O lirismo, denunciativo de uma voz extremamente consciente, aparece em meio a um pensamento do urbano no Livro do desassossego, de autoria compartilhada com Bernardo Soares e Vicente Guedes - como indica Jerónimo Pizarro (2013). Vozes de ser que é não 
ser, engendrando uma narrativa que preconiza o desassossegado caminho romanesco a ser percorrido por Saramago, já no final do século, seguindo trilhas pessoanas:

Sou os arredores de uma vila que não há, o comentário prolixo a um livro que se não escreveu. Não sou ninguém, ninguém. Não sei sentir, não sei pensar, não sei querer. Sou uma figura de romance por escrever, passando aérea, e desfeita sem ter sido, entre os sonhos de quem me não soube completar (PESSOA, 1999, p. 257-258).

Antes de avançarmos em nossa análise da condição autoral — ortonímica, heteronímica ou romanesca - no espaço, a partir da crença no "não ser" evocada pelo Livro do desassossego, precisamos acionar o filósofo Mikhail Bakhtin:

A estrutura totalmente nova da imagem do homem é a consciência como centro do outro [...] Essa consciência não se insere na moldura da consciência do autor, revela-se de dentro como uma consciência situada fora e ao lado, com o qual o autor entra em relações dialógicas (BAKHTIN, 2006, p. 338).

Com Bakhtin (além de Freud e Pessoa), redefinimos a heteronímia pessoana: a imagem do outro é consciente e autônoma, não importa que se origine no dentro, mas sim que se situe em condição de diálogo inacabado: fora e ao lado suscitando relações dialógicas. O autor primário do Ano da morte de Ricardo Reis constrói uma arena, labiríntica e borgiana como o próprio romance. José Saramago configura o Ricardo Reis de Pessoa agora como seu Ricardo Reis: um ser humano, carnal, independente do ortônimo em seus pensamentos e atos. Assim, o erotismo faz descer as musas poéticas das Odes: Lídia e Marcenda aproximam-se fisicamente e palavralmente do antigo contemplador, e a cidade de Lisboa torna-se uma realidade-palco para estas vivências essencialmente cotidianas.

O Reis de José volta vivo porque o Pessoa de José é um defunto. Sente sono porque a Europa dorme, tem as retinas fatigadas porque uma flor ainda não nasceu no asfalto, enquanto erigem estatuárias. Recorde-se que, em princípios do livro, enquanto as crianças caeirianas dizem vários nomes, o narrador descreve a chegada de Ricardo Reis de seu exílio no Brasil. Fernando Pessoa "não o matou antes de morrer", isso fez o arguto Saramago. O narrador, contudo, segue a tradição do semi-heterônimo Bernardo Soares ou de quantos sejam, e escreve em prosa - prosaísmo e experiência urbana:

Já me cansa a rua, mas não, não me cansa - tudo é rua na vida. Há a taberna defronte, que vejo se olho por cima do ombro direito; e há o convento defronte, que vejo se olho por cima do ombro esquerdo; e, no meio, que não verei se me não voltar de todo, o sapateiro enche de som regular o portão do escritório da Companhia Africana. [...] Cansar-me a rua? Canso-me só quando penso. Quando olho a rua, ou a sinto, não penso (PESSOA, 1999, p. 342). 
Nesta fórmula social de lugar "ocupado", os passeios de Ricardo Reis representam a oscilação do desassossego. Uma maneira de reconquistar o seu lugar na cidade recuperada após 16 anos de Brasil, ou melhor dito, recuperada numa vida recomposta - entre seres de papel:

Da sua janela sem cortinas Ricardo Reis olhava o largo rio, para poder ver melhor apagou a luz do quarto, onde estava, caía do céu uma poalha de luz cinzenta que escurecia ao pousar, sobre as águas pardas deslizavam os barcos cacilheiros já de fanais acesos, ladeando os navios de guerra, os cargueiros fundeados, e, quase a esconder-se por trás do perfil dos telhados, uma última fragata que se recolhe à doca, como um desenho infantil, tarde tão triste que do fundo da alma sobe uma vontade de chorar, aqui mesmo, com a testa apoiada na vidraça, separado do mundo pela névoa da respiração condensada na superfície lisa e fria, vendo aos poucos diluir-se a figura contorcida do Adamastor, perder sentido a sua fúria contra a figurinha verde que o desafia, invisível daqui e sem mais sentido do que ele (SARAMAGO, 2010, p. 210-211).

O espetáculo de contemplação mescla o poeta, a festa do ano-novo, que anuncia a morte do personagem Pessoa e a ascensão do totalitarismo, os comícios, as idas ao teatro, os velhos observando os tiros no Tejo. Não são apenas momentos paradigmáticos do romance para representar a identidade cultural portuguesa, mas também pretextos para descrever o corpo coletivo localizado em nós emblemáticos da história. Na arte, como no romance de José Saramago, a tragédia não põe fim ao labirinto. Assim, ao caminhar por tempos sobrepostos e lisboas liminares, o romance mistura-se à biografia dos poetas e insere-se no devir da história. Escrever para ressuscitar. Ressuscitá-la, levantá-la da morte no ano que seria o de sua morte.

Mesmo em 1936, 1984 ou 2019 há a possibilidade de ressurgimento da poesia da vida: pelo enigma do enredo deixado por Ricardo Reis, mas, sobretudo pela composição que não prescinde da poesia mesmo em tempos de desassossegos grandes. $\mathrm{Na}$ tumba visitada por Ricardo Reis, onde deveria jazer o poeta do Orfeu, a única silenciosa, mas viva palavra que ecoa, deve ser: poesia.

\section{Referências}

ALBERTO CAEIRO [Fernando Pessoa]. Poemas completos de Alberto Caeiro. Obra poética. Org. Ma A. Galhoz. Rio de Janeiro: José Aguilar, 1960. p. 133-191.

ÁlVARO DE CAMPOS [Fernando Pessoa]. Poesias de Álvaro de Campos. Obra poética. Org. $M^{a}$ A. Galhoz. Rio de Janeiro: José Aguilar, 1960. p. 249-394.

BAKHTIN, Mikhail. Estética da criação verbal. 4. ed. Tradução: Paulo Bezerra. São Paulo: Martins Fontes, 2006.

BENJAMIN, Walter. Magia e técnica, arte e política. Tradução: Sérgio Paulo. São Paulo: Brasiliense, 1994.

. Passagens. Ed. Org. por Willi Bolle. Tradução: Irene Aron e Cleonice Paes Barreto Mourão. 2. ed. Belo Horizonte: Editora UFMG, 2018. 3 v. 
BORGES, Jorge Luis. Examen de la obra de Herbert Quain. In. Ficciones. 3. ed. Buenos Aires: Debolsillo, 2011. p. 77-85.

CALVINO, Italo. As cidades invisíveis. Tradução: Diogo Mainardi. São Paulo: Companhia das Letras, 1990.

CERDEIRA, Teresa Cristina. O avesso do bordado: ensaios de literatura. Lisboa: Caminho, 2000.

FERREIRA, Sandra. Memento mori: aspectos satírico-filosóficos em As intermitências da morte, de José Saramago. XII Congresso Internacional da ABRALIC-Centro, Centos-Ética, Estética. Curitiba: UFPR, 2011. Anais [...]. Disponível em: http://www.abralic.org.br/eventos/ cong2011/AnaisOnline/resumos/TC1122-1.pdf. Acesso em: 10 ago 2019.

FREUD, Sigmund. O mal-estar na civilização. In. O futuro de uma ilusão, o mal-estar na civilização e outros trabalhos. Obras psicológicas completas de Sigmund Freud: edição standard brasileira. Tradução: Jayme Salomão. Rio de Janeiro: Imago, 2006. p. 73-148. v. 21.

GALHOZ, Maria Aliete. Fernando Pessoa: um encontro de poesia. In: PESSOA, Fernando. Obra poética. 3. ed. Org. Ma A. Galhoz. Rio de Janeiro: Nova Aguilar, 2005. p. 15-69.

GOMES, Renato Cordeiro. Todas as cidades, a cidade: literatura e experiência urbana. Rio de Janeiro: Rocco, 1994.

HOBSBAWM, Eric. Era dos extremos: o breve século XX: 1914-1991. Tradução: Marcos Santarrita. São Paulo: Companhia das letras, 2008.

LOURENÇO, Eduardo. Fernando Pessoa: rei da nossa Baviera. Lisboa: Gradiva, 2008.

MOSCA, João. Salazar e a política económica do Estado Novo, Revista Lusíada. História. Série 2, Lisboa, n. 4, p. 339-364, 2007.

PERRONE-MOISÉS, Leyla. Fernando Pessoa: aquém do eu, além do outro. São Paulo: Martins Fontes, 2001.

PESSOA, Fernando. Obra poética. Org. Maria Aliete Galhoz. 9. ed. Rio de Janeiro: Nova Aguilar, 1960.

Livro de desassossego: composto por Bernardo Soares, ajudante de guarda-livros na cidade de Lisboa. Org. Richard Zenith. 2. ed. São Paulo: Companhia de Letras, 1999.

PIZARRO, Jerónimo. Prefácio. In: PESSOA, Fernando. Livro do desassossego. Ed. Jerónimo Pizarro. Rio de Janeiro: Tinta-da-china, 2013. p. 11-29.

RICARDO REIS [Fernando Pessoa]. Odes de Ricardo Reis. Obra poética. Org. Ma A. Galhoz. Rio de Janeiro: José Aguilar, 1960. p. 193-247.

SARAMAGO, José. O ano da morte de Ricardo Reis. 2. ed. São Paulo: Companhia das Letras, 2010.

SILVA JR., Augusto Rodrigues da. Tanatografia e morte literária: decomposições biográficas e reconstruções dialógicas. ComCiência, Campinas, n. 163,p. 1-8, nov. 2014. Disponível em: http:// comciencia.scielo.br/scielo.php?script=sci_arttext\&pid=S1519-76542014000900012\&lng=pt \&nrm=isso. Acesso em: 12 mar 2019.

. Centroestinidades e geopoesia: casa de morar Niemar é a poesia. In: MEDEIROS, A. C. M. et al. (Orgs.). Os parceiros de Águas Lindas: ensino de literatura pelas letras de Goiás. Goiânia: Pé de Letras, 2018. p. 53-80. 


\section{Minicurrículo}

Ana Clara Magalhães de Medeiros é professora de Estudos Literários na Universidade Federal de Alagoas (Ufal). Pesquisadora permanente do Programa de Pós-Graduação em Letras e Linguística (PPGLL/Ufal). Doutora em Literatura pela Universidade de Brasília (UnB).

Augusto Rodrigues da Silva Junior é professor de Literatura Comparada na UnB. Pesquisador permanente do Programa de Pós-Graduação em Literatura (Póslit/UnB). Pós-doutorado em Literatura pela Universidade do Minho, Portugal. Doutor em Literatura Comparada pela Universidade Federal Fluminense. 